\title{
Otherwise unstable structures self-assemble in the cavities of cuboctahedral coordination cages
}

\author{
Felix J. Rizzuto, William J. Ramsay, Jonathan R. Nitschke* \\ University of Cambridge, Department of Chemistry, Cambridge UK, CB2
}

\begin{abstract}
We present a method for the directed self-assembly of interlocked structures and coordination complexes in a set of metal-organic hosts. New homo- and hetero-leptic metal complexes - species that cannot be prepared outside - form within the cavities of cuboctahedral coordination cages. When linear bidentate guests and macrocycles are sequentially introduced to the host, a rotaxane is threaded internally; the resulting ternary host-guest complex is a new kind of molecular gyroscope. Tetradentate guests segregate the cavities of these cages into distinct spaces, promoting new stoichiometries and modes of ligand binding to metal ions. The behaviours of bound complexes were observed to alter markedly as a result of confinement: in situ oxidations and spin transitions, neither of which occur ex situ, were both observed to proceed. By providing a tailored space for new modes of coordination-driven self-assembly, the inner phases of cuboctahedral coordination cages provide a new medium for synthetic coordination chemistry.
\end{abstract}

\section{INTRODUCTION}

Biomolecules use coordinated metal ions to harvest light, convert energy and regulate respiration; ${ }^{1}$ industrial technologies use metal coordination processes for fuel production, ${ }^{2}$ drug synthesis $^{3}$ and catalysis. ${ }^{4}$ A wealth of coordination complexes have thus been generated synthetically to mimic and extend these applications: ${ }^{5}$ currently, the Cambridge Crystallographic Data Centre holds more than 420,000 transition metal-containing crystal structures ( $c a .47 \%$ of the database), prepared using either solution- or solid-state techniques. ${ }^{6}$ However, many discrete complexes are not synthetically accessible: for instance, polydentate ligands often generate infinite networks, ${ }^{7}$ and labile structures cannot be isolated from dynamic product mixtures. ${ }^{8}$ The finite number of available methods to synthesise discrete metal-organic complexes has limited the production of new coordination compounds, along with their range of applications. ${ }^{9}$

A subset of discrete metal-organic complexes are polynuclear and three-dimensional, with multi-valent metal ions and ligands arranged in a polyhedral scaffold ${ }^{10}$ that frames a guest-binding central cavity. ${ }^{11}$ Guest molecules often experience conformational restriction in this confined environment, lending new modes of reactivity to otherwise inert species. ${ }^{12}$ The specific arrangements and orientations of bound guests within these synthetic systems can modulate interactions between components, generating systems that regulate binding events, ${ }^{13}$ catalyse reactions ${ }^{14}$ and organise collections of guests $^{15}$ in new ways. ${ }^{16}$ The design of systems that 
demonstrate different modes of cooperation could lead to the development of new modes of self-assembly, ${ }^{17}$ where different structural elements harmonise to generate complexity ${ }^{18}$.

The structural rigidity of metal-organic cages makes them ideal candidates for directing the internal assembly of coordination systems and otherwise unstable species. ${ }^{19}$ In the case of the $O$-symmetric architectures described herein, each of their three pairs of square faces are parallel, enclosing a cubic void space. We hypothesised that including coordination sites in the centres of ligands within these structures might direct the assembly of discrete structures within their cavities. This strategy proved successful. We thus present herein a set of methods for assembling coordination complexes within coordination cages, including a rotaxane-based molecular gyroscope. The structures bound within these cages do not exist outside them, due to the lability of the coordination interactions that hold them together. The high degree of cooperativity imposed by the regular array of coordination sites embedded in the frameworks of our cages could thus stabilise species that are otherwise too labile to exist in appreciable concentration. The confinement of self-assembled products within coordination cage cavities led to unique guest behaviour: guest compression and preorganisation led to the favouring of ordinarily inaccessible spin- and oxidation-state changes of internally-bound metal ions.

\section{RESULTS \& DISCUSSION}

\section{Host-guest chemistry of 1}

Dinuclear $\mathrm{Rh}_{2}{ }_{2}$ paddlewheel $\mathbf{A}$ was synthesised from commercial starting materials as described in Supplementary Section 4. The reaction of A (6 equiv) with 2-formylphenanthroline (P; 24 equiv) and cadmium(II) trifluoromethanesulfonate (OTf', 12 equiv) generated new cuboctahedron $\mathbf{1}$ as the uniquely observed product (Figure 1a). The fourfold symmetry of subcomponent A was retained in the spectrum of 1, consistent with $O$ point symmetry. ESI-MS confirmed the $\mathrm{Cd}^{\mathrm{II}}{ }_{12} \mathbf{L}^{\mathbf{A}}{ }_{6}$ composition of $\mathbf{1}$.

Cage 1 crystallised in the cubic space group Pn3--; both enantiomers are present in the unit cell. The crystal structure showed a cuboctahedral arrangement of $\mathrm{Cd}^{\mathrm{II}}$ ions enclosing a cubic cavity of $c a .1750 \AA^{3}$ (Figure 1b).

$\mathrm{Rh}_{2}{ }_{2}$ dicarboxylate paddlewheels exhibit rich axial coordination chemistry. ${ }^{20}$ Negativelycharged and neutral donors were thus observed to bind to the $\mathrm{Rh}^{\mathrm{II}}$ coordination sites of $\mathbf{1}$ in fast exchange on the NMR timescale (Supplementary Section 6). Linear ditopic guests (tetrazine- and phenylene-centered dipyridyl guests were observed to bind in slow exchange at the endo- $\mathrm{Rh}^{\mathrm{II}} \mathrm{sites}$ of 1 (Figures S12-16). Such internally-binding ligands bridged the cavity of 1 (Figure 1f), as reflected in the three unique ligand environments identified in NMR spectra of the host. Larger 
anions such as $\mathrm{B}_{12} \mathrm{~F}_{12}{ }^{2-}, \Delta$-TRISPHAT ${ }^{21}$ and tetraphenylborate also produced distinct ${ }^{1} \mathrm{H}$ NMR shifts upon addition to $\mathbf{1}$, consistent with fast-exchange binding on the NMR timescale.

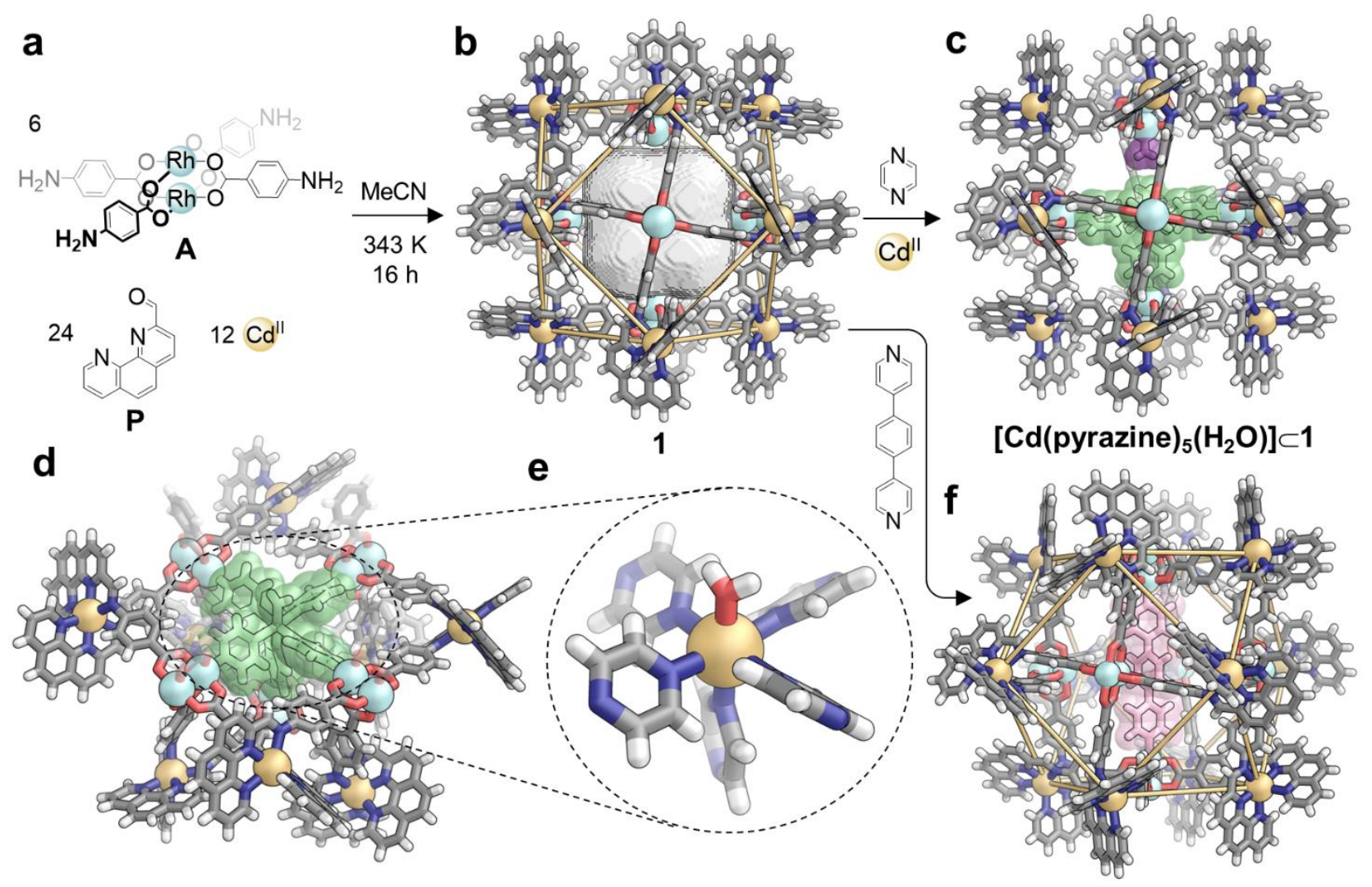

Figure 1. Preparation of, and metal complex assembly within, 1. (a) The self-assembly of subcomponents $\mathbf{A}$ and $\mathbf{P}$ with $\mathrm{Cd}^{\mathrm{II}}$ generated 1. (b) Crystal structure of 1, where the framework symmetry is highlighted with yellow lines connecting metal centres and the cavity volume is displayed as a white surface. (c) Crystal structure of $\left[\mathrm{Cd}(\text { pyrazine })_{5}\left(\mathrm{H}_{2} \mathrm{O}\right)\right] \subset \mathbf{1}$, generated by the addition of $\mathrm{Cd}^{\mathrm{II}}$ and pyrazine to $\mathbf{1}$, with the encapsulated complex highlighted in green and the water molecule coordinated to an endo- $\mathrm{Rh}^{\mathrm{II}}$ site highlighted in purple. (d) View of $\left[\mathrm{Cd}(\text { pyrazine })_{5}\left(\mathrm{H}_{2} \mathrm{O}\right)\right] \subset \mathbf{1}$ with the top half of the cage removed, showing only those $\mathrm{Rh}_{2}{ }_{2}$ units bound to the encapsulated complex. (e) Cutaway of the encapsulated $\left[\mathrm{Cd}(\text { pyrazine })_{5}\left(\mathrm{H}_{2} \mathrm{O}\right)\right]^{2+}$ complex. (f) MM3 molecular model of a linear dipyridyl guest (highlighted in pink) bound between cofacial $\mathrm{Rh}_{2}{ }_{2}$ sites in 1. Externally-coordinated ligands, disorder, solvent molecules and anions are omitted for clarity $(\mathrm{Cd}=$ yellow, $\mathrm{Rh}=\mathrm{cyan}, \mathrm{C}=\mathrm{grey}, \mathrm{N}=\mathrm{blue}, \mathrm{O}$ $=$ red, $\mathrm{H}=$ white).

As the internal $\mathrm{Rh}^{\mathrm{II}}$ sites of $\mathbf{1}$ bound bidentate ligands, we investigated the affinity of $\mathbf{1}$ for other polydentate potential binders. Pyrazine bound to $\mathbf{1}$ in fast exchange on the NMR timescale (Figure S19). Remarkably, the addition of $\mathrm{Cd}(\mathrm{OTf})_{2}$ following the saturation of 1 with pyrazine (20 equiv) led to further shifts in the ${ }^{1} \mathrm{H}$ NMR signals of $\mathbf{1}$, suggesting interaction of $\mathrm{Cd}^{\mathrm{II}}$ with the cage and encapsulated pyrazine: broadening of the cage signals was observed, suggesting cage desymmetrisation. Single-crystal X-ray measurement revealed that a unique metal complex was bound within 1 (Figure 1c-e).

The encapsulated metal complex consisted of a $\mathrm{Cd}^{\mathrm{II}}$ ion coordinated to five molecules of pyrazine and one $\mathrm{H}_{2} \mathrm{O}$ (Figure 1e). To accommodate its heteroleptic guest, the cage distorts slightly: whereas antipodal endo- $\mathrm{Rh}^{\mathrm{II}}-\mathrm{Rh}^{\mathrm{II}}$ distances spanned $15.5 \AA$ in the crystal structure of $\mathbf{1}$, 
this distance was observed to contract to $14.8 \AA$ around the equatorial belt of the cadmium pentapyrazine adduct, breaking the cubic symmetry of the void. The law of coordinative saturation $^{22}$ thus shaped the nature of the product: only a pair of water ligands are small enough to bind simultaneously to the endo-facing $\mathrm{Rh}^{\mathrm{II}}$ atom and the encapsulated $\mathrm{Cd}^{\mathrm{II}}$ ion. Unusually, hydrogen atoms on both $\mathrm{H}_{2} \mathrm{O}$ molecules are in close contact (O-O distance $3.5 \AA$ ). These two water molecules are not geometrically capable of engaging in hydrogen bonding with each other, instead forming hydrogen bonds with two bridging triflate anions inside the cavity of $\mathbf{1}$. This configuration thus stabilised an otherwise energetically unfavourable state through coordination (Figure 1c) and anion interactions.

Previous attempts to generate pentakis(pyrazine) complexes have relied on the preorganisation of pyrazine moieties into a pentadentate ligand. ${ }^{23}$ The coordination motif presented here is instead organised by the host; $\left[\mathrm{Cd}(\text { pyrazine })_{5}\left(\mathrm{H}_{2} \mathrm{O}\right)\right]^{2+}$ is uniquely stabilised within cage $\mathbf{1}$ and does not exist outside of it. Pyrazine is usually a poor bridging ligand - coordination at one nitrogen atom tends to withdraw electron density from the second, diminishing its coordination ability. ${ }^{24}$ Synergic effects within the cavity of 1 led to the stabilisation of a unique pentakis(pyrazine)Cd ${ }^{\mathrm{II}}$ center, in which all pyrazine ligands bridge dications within a $26+$ charged species. Pyrazine, previously employed for the generation of heteroleptic $\operatorname{architectures}^{25}$ and coordination polymers, ${ }^{26}$ thus adopts a new role in binding labile $\mathrm{Cd}^{\mathrm{II}}$ within a discrete, soluble structure.

\section{A more accommodating host for coordination chemistry}

Following the demonstration of discrete complex stabilisation within 1, we hypothesised that a larger cavity, matched to the dimensions of potential guests, might lead to the generation of a wider range of new endohedrally-bound metal complexes.

We thus synthesised new cage 2 , in which $\mathrm{Zn}^{\mathrm{II}}$ porphyrins define the faces of a cuboctahedron. The reaction of subcomponents $\mathbf{B} \quad(6$ equiv $)$ and $\mathbf{P}(24$ equiv $)$ with zinc bis(trifluoromethanesulfonyl)imide ( $\mathrm{NTf}_{2}^{-}, 12$ equiv) yielded $O$-symmetric $\mathrm{Zn}^{\mathrm{II}}{ }_{12} \mathbf{L}^{\mathbf{B}}{ }_{6}$ assembly 2 as the only product observed by ESI-MS and ${ }^{1} \mathrm{H}$ NMR spectroscopy (Figure 2a). Slow rotation of the phenylene protons was observed on the NMR timescale, enabling differentiation between interior and exterior guest binding by ${ }^{1} \mathrm{H}$ NOESY spectroscopy (Figure S20).

Cage 2 has a larger distance connecting porphyrin-bound $\mathrm{Zn}^{\mathrm{II}}$ centers ( $c a .19 \AA$, based on MM3 molecular models, Figure S2), as compared to the distance between $\mathrm{Rh}^{\mathrm{II}}$ centers (15.5 $\AA$ ) in 1. The larger cavity of this structure ( $c a .3000 \AA^{3}$ ) enabled a wider range of guests to be encapsulated, thus permitting greater diversity in the assembly of new species within the cage cavity. 
a

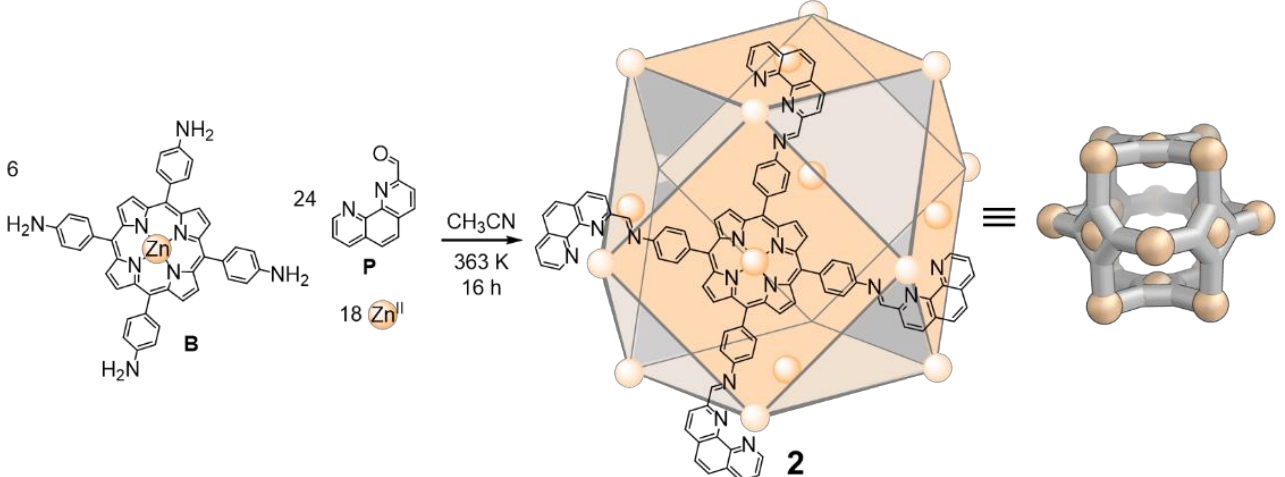

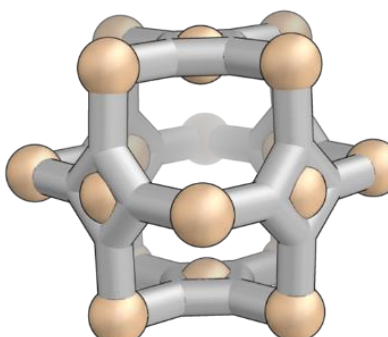
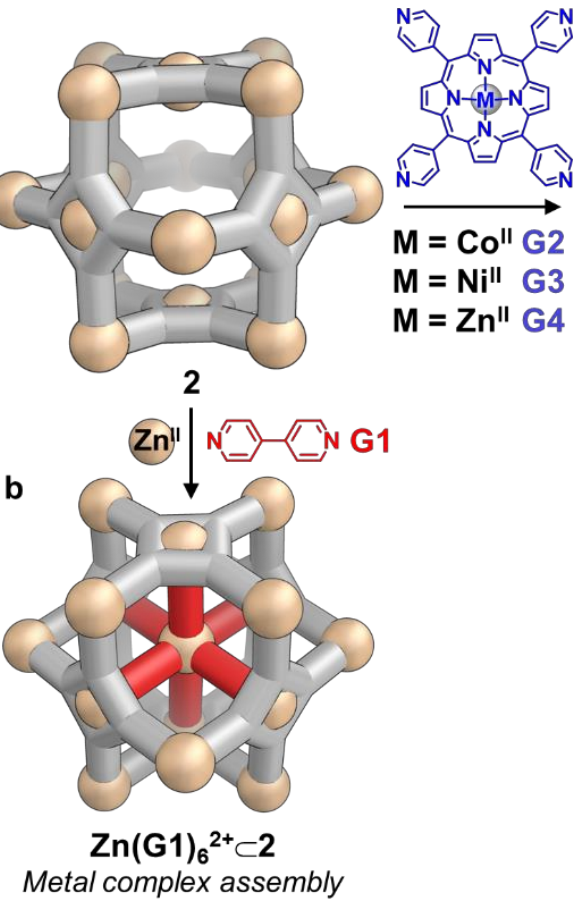
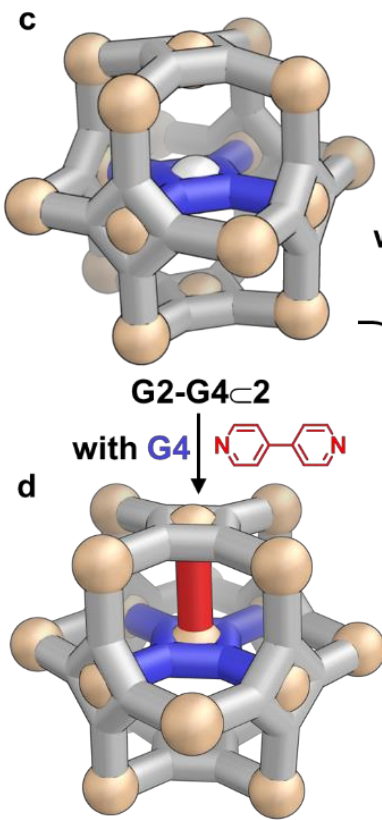

G1.G4 $\subset 2$

Uniaxial ligation

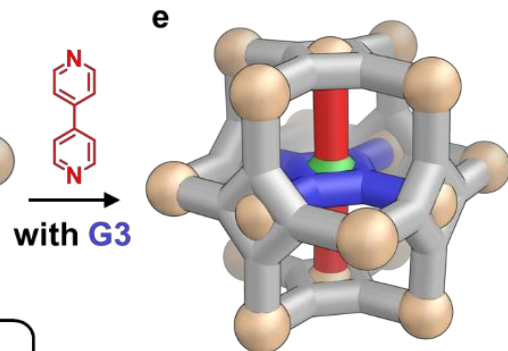

$(\mathbf{G} 1)_{2} \cdot \mathbf{G} 3 \subset 2$

Nill spin transition
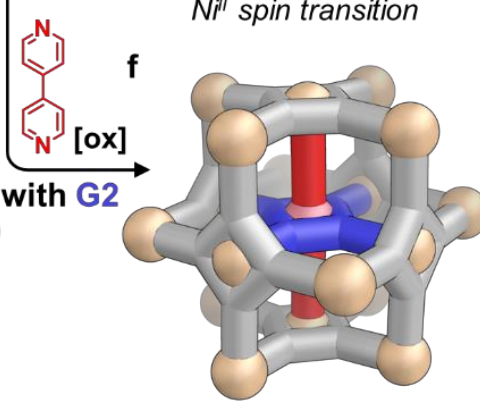

$(\mathrm{G} 1)_{2} \cdot \mathrm{G2}^{+} \subset 2$

Coll $\rightarrow$ Co III oxidation

Figure 2. Different coordination complexes and guest binding configurations within 2. (a) The reaction of $\mathbf{P}, \mathbf{B}$ and $\mathrm{Zn}\left(\mathrm{NTf}_{2}\right)_{2}$ yielded 2. (b) The addition of $\mathbf{G 1}$ to a solution of $\mathbf{2}$ in $\mathrm{MeCN}$ generated $\mathrm{Zn}(\mathbf{G 1})_{6}{ }^{2+}$ bound within 2. (c) Metalloporphyrin guests G2-G4 divide the cavity of $\mathbf{2}$ upon binding, such that subsequent binding of G1 brought about unique coordination chemistry within the cavity of 2: (d) a single axial ligand bridged one of the two divisions in the case of G4; (e) a NiII spin transition occurred during the binding of two molecules of $\mathbf{G 1}$ within $\mathbf{G 3} \subset \mathbf{2}$; (f) $\mathrm{Co}{ }^{\mathrm{II}}$ $\rightarrow \mathrm{Co}^{\mathrm{III}}$ oxidation spontaneously occurred under air following the addition of $\mathbf{G 1}$ to $\mathbf{G} \mathbf{2} \subset \mathbf{2}$.

The addition of 4,4'-bipyridine (G1) to a solution of 2 containing $\mathrm{Zn}^{\mathrm{II}}$ (6 equiv excess) resulted in the internal binding of G1; slow exchange binding of G1 was observed on the NMR timescale (Supplementary Section 8.1). No further binding of G1 was observed once six equivalents had been added. ESI-MS revealed a charge increase of 2 from $24+$ to $26+$, with 2 encapsulating one $\mathrm{Zn}{ }^{\mathrm{II}}$ ion and up to six molecules of $\mathbf{G 1}$ simultaneously. The slow exchange binding of this guest by NMR, with maintenance of $O$ point symmetry, suggests all-or-nothing cooperative binding of six molecules of $\mathbf{G 1}$ around $\mathrm{Zn}$, consistent with the formation of an octahedral metal complex of formula $\mathrm{Zn}(\mathbf{G 1})_{6}{ }^{2+}$ within 2 (Figure $2 \mathrm{~b}$ ) that fragments upon ionisation. When G1 was titrated into purified 2, it was observed to bind in fast exchange on the NMR timescale; excess $\mathrm{Zn}^{\mathrm{II}}$ was necessary to bring about cooperative binding. In the absence of $\mathbf{2}$, no discrete metal-organic 
species could be identified spectroscopically when $\mathbf{G 1}$ and $\mathrm{Zn}^{\mathrm{II}}$ were mixed in a 6:1 ratio, only insoluble materials.

Fourfold-symmetric tetrapyridyl metalloporphyrins containing $\mathrm{Co}^{\mathrm{II}}, \mathrm{Ni}^{\mathrm{II}}$ or $\mathrm{Zn}^{\mathrm{II}}(\mathbf{G} 2, \mathbf{G 3}$ and G4, respectively) also bound within 2 (Figure 2c, Supplementary Section 8.2). The binding of G2G4 led to $O \rightarrow D_{4}$ desymmetrisation of the host framework by NMR: the top and bottom ligands of the host (as well as the centrally-bound guest) maintain fourfold symmetry, while the vertical and horizontal arms of the four ligands spanning the equator of the structure have distinct ${ }^{1} \mathrm{H}$ NMR environments (Figure 3). ${ }^{1} \mathrm{H}-{ }^{1} \mathrm{H}$ NOE correlations were observed between the interior-facing phenylene protons of $\mathbf{L}^{\mathbf{B}}$ and the pyridyl protons of $\mathbf{G 3}$ and $\mathbf{G 4}$, which were shielded by the ring current of the cage porphyrins. Although no signals for paramagnetic guest $\mathbf{G 2}$ could be identified, broadening of the interior-facing phenylene protons of the cage and threefold splitting of cage signals were observed, consistent with the same mode of binding as observed for G3 and G4. We were unable to follow the titration of these guests with $\mathbf{2}$ so as to derive binding constants, given the insolubility of G2-G4 in MeCN.

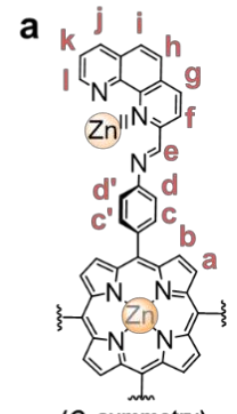

$\left(C_{4}\right.$ symmetry)

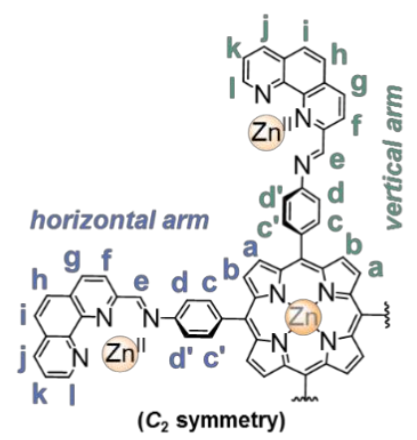

b

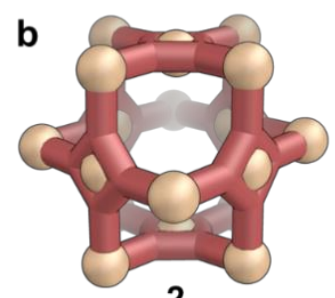

2

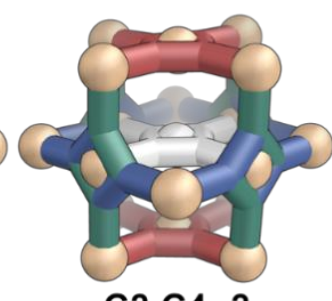

G2-G4 $\subset 2$

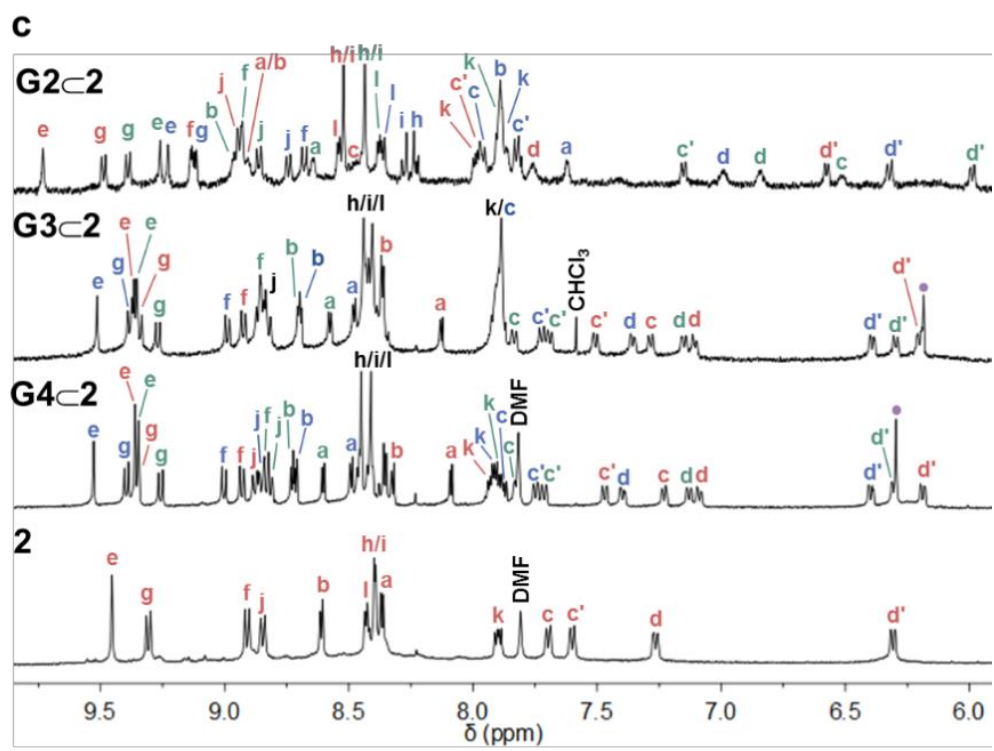

Figure 3. Encapsulation of guests within 2 led to desymmetrisation of the cage framework. (a) Ligand proton environments of $\mathbf{2}$ upon porphyrin encapsulation, where $\mathrm{c}^{\prime}$ and $\mathrm{d}^{\prime}$ are the outward-facing protons of the phenylene rings. (b) Equivalent environments within 2 upon binding G2-G4, colour-coded to match the environments in (a). In the absence of guests, all ligands in $\mathbf{2}$ have fourfold symmetry; in G2-G4 $\subset \mathbf{2}$, the ligands bound to the guest have twofold symmetry (blue and green arms), while the ligands parallel to the guest retain fourfold symmetry (red arms).

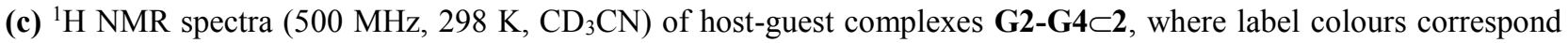
to the ligand arm environments, black letters correspond to signals coincident within each desymmetrised environment, and purple circles mark signals from the encapsulated guest.

The binding of these porphyrin guests thus partitions the cavity of $\mathbf{2}$ into two distinct, symmetry-equivalent spaces, above and below the encapsulated metalloporphyrin. To further explore the potential of these species to form encapsulated metal complexes, we investigated the 
secondary encapsulation of 4,4'-bipyridine G1, which models suggested would provide an optimal bridge between host and guest porphyrin metal centres (Figure $2 \mathrm{~d}-\mathrm{f}$ ).

For all three metalloporphyrin guests, we observed two molecules of bipyridine $\mathbf{G 1}$ to bind to the host-guest complexes by ESI-MS (Supplementary Section 8.3). UV-Vis titrations of G1 into host-guest complexes G2-G4 $\subset \mathbf{2}$ fitted well to 1:2 binding isotherms; anticooperative binding was observed in each case, where the ratio of the first to second binding event $\left(4 K_{2} / K_{1}\right.$, taking in to account the binding microstates) $)^{27}$ was in the range $0.02-0.07$. The identity of the metal ion is understood to determine the axial coordination mode of metalloporphyrins: ${ }^{28} \mathrm{Co}^{\mathrm{II}}$ porphyrins readily bind two ligands, whereas $\mathrm{Zn}^{\mathrm{II}}$ porphyrins bind only one ligand, and low-spin $\mathrm{Ni}^{\mathrm{II}}$ porphyrins only bind ligands in a very electron-deficient environment, which favours high-spin $\mathrm{Ni}^{\mathrm{II}} \cdot{ }^{29}$ Within 2 , however, each bound porphyrin guest displayed distinct and atypical coordination chemistry. The confinement of metalloporphyrins within 2 facilitated both $\mathrm{Co}^{\mathrm{II}} \rightarrow \mathrm{Co}^{\mathrm{III}}$ oxidation and $\mathrm{Ni}^{\mathrm{II}}$ low $\rightarrow$ high spin transitions, neither of which occurred outside the cage cavity.

The titration of $\mathbf{G 1}$ into $\mathbf{G} \mathbf{2} \subset \mathbf{2}$ produced a distinct ${ }^{1} \mathrm{H}$ NMR spectrum consistent with fast exchange binding on the NMR timescale. However, owing to the paramagnetic $\mathrm{Co}^{\mathrm{II}}$ centre of $\mathbf{G} 2$, no guest peaks could be observed from 233-298 K. After three days at $298 \mathrm{~K}$ under ambient atmospheric conditions, we observed the NMR spectrum of $(\mathbf{G 1})_{2} \cdot \mathbf{G 2} \subset \mathbf{2}$ to exhibit new, sharp peaks. An ESI mass spectrum indicated that the complex had increased in charge from +24 to +25 , suggesting oxidation of the cobalt(II) centre to cobalt(III) by atmospheric oxygen (Figure $4 \mathrm{a}) .{ }^{1} \mathrm{H}$ NMR signal integration indicated the presence of two $\mathbf{G 1}$ axial ligands, with $D_{4}$ symmetry overall (Figure $4 \mathrm{~b}$ ). We infer the oxidation potential of the $\mathrm{Co}^{\mathrm{II}}$ centre to decrease as a result of $\sigma$-donation from G1 ${ }^{30}$ Steric compression, transmitted from the cage framework through $\mathbf{G 1}$ to the cobalt centre, may also stabilise the $\mathrm{Co}^{\mathrm{III}}$ state, which has a smaller coordination sphere. Oxidation of $\mathbf{G 2}$ under ambient conditions only occurred after binding $\mathbf{G 1}$; $\mathbf{G 2} \subset \mathbf{2}$ alone was stable in the $\mathrm{Co}^{\mathrm{II}}$ state in air over the course of 3 months. Likewise, no interaction between $\mathbf{G 2}$ and $\mathbf{G 1}$ was observed in the absence of $\mathbf{2}$, as $\mathbf{G} 2$ is insoluble in $\mathrm{MeCN}$ (as well as $\mathrm{CHCl}_{3}$ and DMSO). Congeners of $\mathbf{G 2}$ dimerise in the presence of $\mathbf{G 1},{ }^{31}$ or else form insoluble networked materials, ${ }^{32}$ whereas within $\mathbf{2}$, a discrete octahedral complex is formed exclusively. 

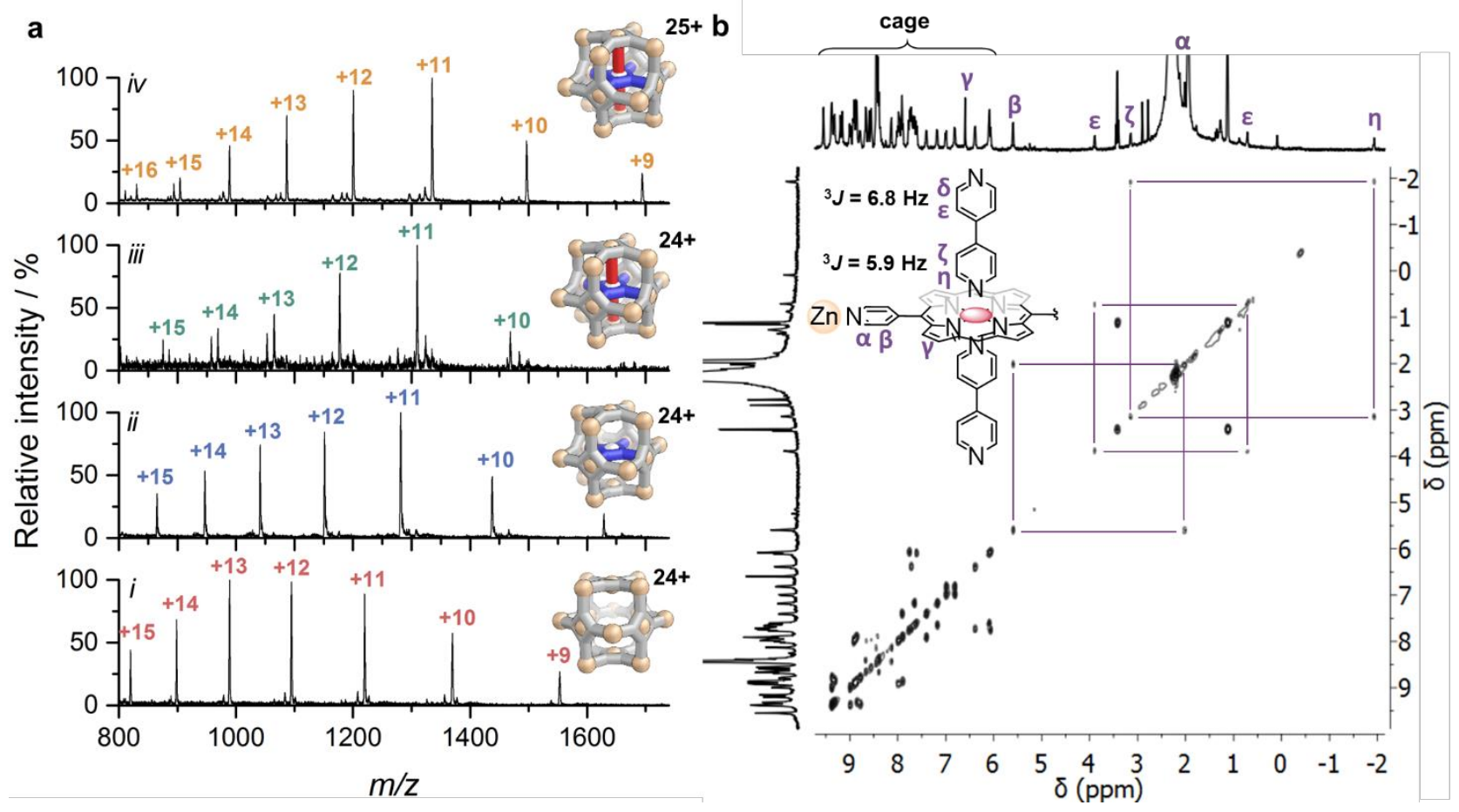

Figure 4. Synthesis of diamagnetic $(\mathbf{G 1})_{2} \cdot \mathbf{G 2}{ }^{+} \subset \mathbf{2}$. (a) ESI mass spectra charting the preparation of $(\mathbf{G 1})_{2} \cdot \mathbf{G 2} 2^{+} \subset \mathbf{2}$ from 2, showing spectra of (i) 2; (ii) G2 $\subset \mathbf{2}$; (iii) (G1) $)_{2} \cdot \mathbf{G 2} \subset \mathbf{2}$; and (iv) (G1) $)_{2} \cdot \mathbf{G 2}^{+} \subset \mathbf{2}$. (b) ${ }^{1} \mathrm{H}-{ }^{1} \mathrm{H}$ COSY NMR spectrum (400 $\left.\mathrm{MHz}, 298 \mathrm{~K}, \mathrm{CD}_{3} \mathrm{CN}\right)$ of $(\mathbf{G 1})_{2} \cdot \mathbf{G 2}^{+} \subset \mathbf{2}$, with guest signals and ${ }^{3} J$ correlations in purple.

The addition of $\mathbf{G 1}$ to nickel-porphyrin-containing $\mathbf{G 3} \subset \mathbf{2}$ likewise led to broadening and shifting of the product ${ }^{1} \mathrm{H}$ NMR signals. Neither the encapsulated porphyrin nor the binding G1 signals could be identified, even at $233 \mathrm{~K}$, although the binding of two molecules of G1 was observed by ESI-MS. Similarities were observed between the proton spectra of paramagnetic $\mathbf{G 2} \subset \mathbf{2}$ and $(\mathbf{G 1})_{2} \cdot \mathbf{G 3} \subset \mathbf{2}$, including the absence of guest signals and broadened interior-facing phenylene proton signals, and the Soret band of G3 was observed to red-shift upon the UV-Vis titration of $\mathbf{G 1}$ into $\mathbf{G} \mathbf{3} \subset \mathbf{2}$. These observations led us to infer that $\mathbf{G} \mathbf{1}$ had bound to the axial $\mathrm{Ni}^{\mathrm{II}}$ sites of $\mathbf{G 3}$ within $\mathbf{2}$, causing the $\mathrm{Ni}^{\mathrm{II}}$ centre to become high-spin. We calculated an effective magnetic moment $\left(\mu_{\text {eff }}\right)$ of 2.5 Bohr Magnetons for $(\mathbf{G 1})_{2} \cdot \mathbf{G 3} \subset \mathbf{2}$ using the Evans method, in good agreement with the spin-only moment of high-spin octahedral $\mathrm{Ni}^{\mathrm{II}}$ (2.8 Bohr Magnetons).

Ni-porphyrins rarely bind axial ligands in the absence of strongly electron-withdrawing porphyrin substituents. ${ }^{33}$ When $\mathbf{G 1}$ was added to $\mathbf{G 3}$ in the absence of $\mathbf{2}$, no interaction between ligand and metalloporphyrin was observed (Figure S72). Preorganisation and host-guest size complementarity thus enabled the generation of this otherwise inaccessible high-spin $\mathrm{Ni}^{\mathrm{II}}$ complex within 2.

The ${ }^{1} \mathrm{H}$ NMR spectrum of zinc-porphyrin-containing $\mathbf{G 4} \subset \mathbf{2}$ underwent desymmetrisation when a sub-stoichiometric amount of G1 was added; following the addition of more than one 
equivalent of G1, the $D_{4}$ symmetry of the host-guest complex was re-established (Figure 5a:i-iii). Upon cooling to $233 \mathrm{~K}$, however, six distinct porphyrin cage environments were observed (Figure 5a:iv). The pyridyl signals of G4 split into two signals of equal intensity, and the four signals attributed to encapsulated G1 shifted upfield. Integration of the proton signals attributed to G1 against those of G4 suggested a 1:1 ratio of these species within 2 . This is consistent with a square pyramidal geometry of the $\mathrm{Zn}^{\mathrm{II}}$-porphyrin centre, wherein $\mathbf{G 4}$ defines the square plane and a single molecule of $\mathbf{G 1}$ binds axially (Figure 5c). We infer that the addition of $>1$ equiv of $\mathbf{G 1}$ led to rapid exchange between the two ligation sites, giving apparent $D_{4}$ symmetry at $298 \mathrm{~K}$.

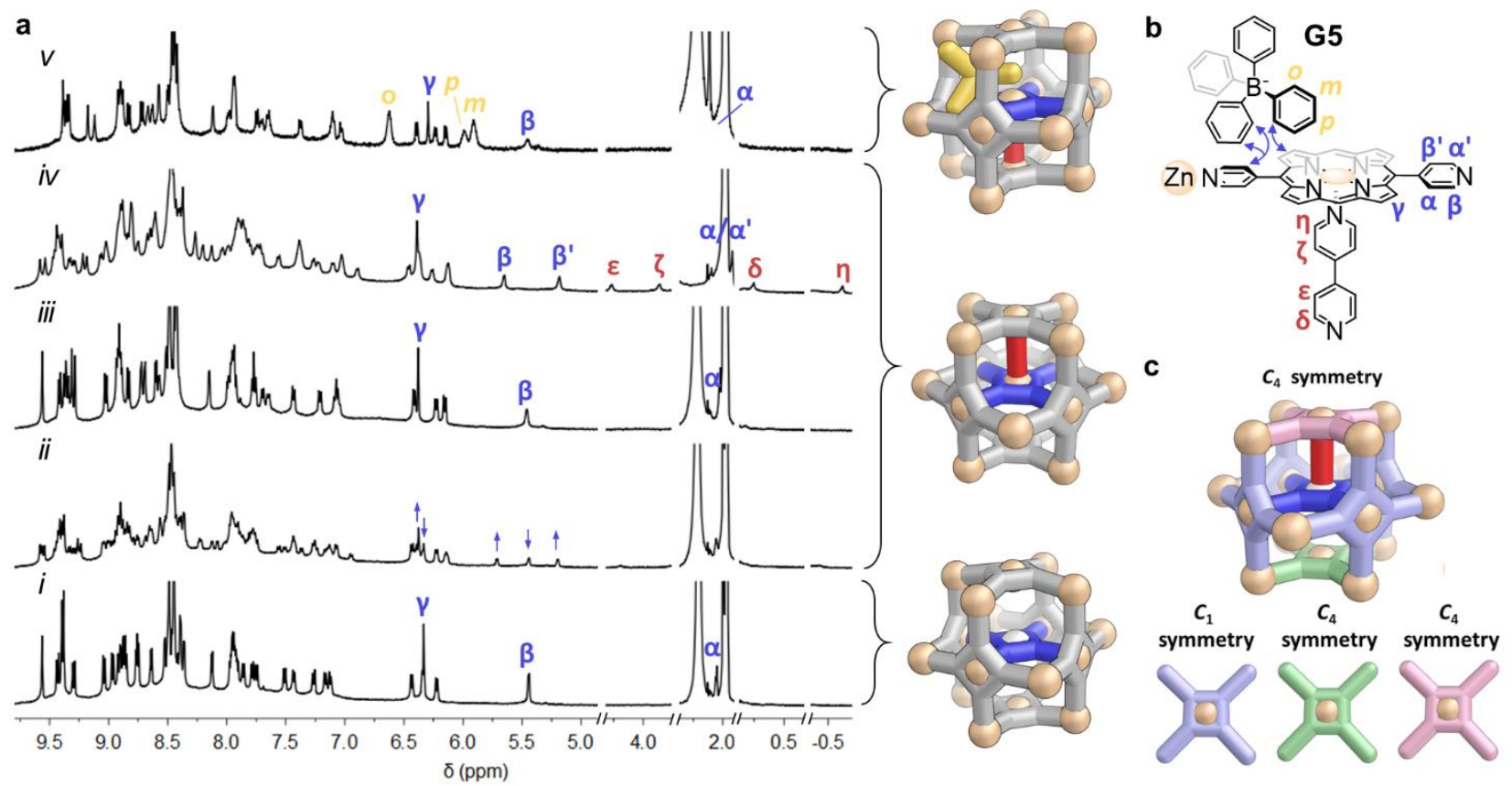

Figure 5. Interactions of $\mathbf{G 1}$ and $\mathrm{BPh}_{4}{ }^{-}$with $\mathbf{G 4} \subset \mathbf{2}$. (a) ${ }^{1} \mathrm{H}$ NMR spectra $\left(500 \mathrm{MHz}, \mathrm{CD}_{3} \mathrm{CN}\right)$ following the addition of $\mathbf{G 1}$ and $\mathbf{G 5}$ to $\mathbf{G 4} \subset \mathbf{2}$ : (i) $\mathbf{G 4} \subset \mathbf{2}$; (ii) at $298 \mathrm{~K}$, the titration of $\mathbf{G 1}$ into a solution of $\mathbf{G 4} \subset \mathbf{2}$ in MeCN desymmetrised the host framework, which proceeded via slow exchange up to a threshold of one equivalent of G1; (iii) rapid exchange of $>1$ equiv of $\mathbf{G 1}$ between the two internal guest sites re-established the original $D_{4}$ symmetry of $\mathbf{G 4} \subset \mathbf{2}$; (iv) cooling this mixture to $233 \mathrm{~K}$, peaks attributed to $\mathbf{G 1} \cdot \mathbf{G 4} \subset \mathbf{2}$ resolved; (v) the addition of ${ }^{n} \mathrm{Bu}_{4} \mathrm{NBPh}_{4} \mathbf{G 5}$ to $\mathbf{G 1} \cdot \mathbf{G 4} \subset \mathbf{2}$ led to shifts consistent with fast exchange $\mathrm{BPh}_{4}{ }^{-}$binding on the NMR timescale at $298 \mathrm{~K}$. (b) The three encapsulated guests, each binding within a specific region of 2, with NOEs between G4 and G5 shown using blue arrows. (c) Diagram showing the symmetry environment of each ligand within $C_{4}$-symmetric $\mathbf{G 1} \cdot \mathbf{G} \mathbf{4} \subset \mathbf{2}$.

A third level of host-guest chemistry was observed within the new void space created in G1-G4 $\subset 2$ (Supplementary Section 8.4). The addition of ${ }^{n} \mathrm{Bu}_{4} \mathrm{NBPh}_{4}$ led to distinct NMR shifts consistent with $\mathrm{BPh}_{4}^{-}(\mathbf{G 5})$ encapsulation in fast exchange on the NMR timescale (Figure 5a:v). ${ }^{1} \mathrm{H}$ NOESY NMR spectroscopy revealed correlations between the ortho and meta protons of G5 and the pyrrolic and pyridyl protons of the encapsulated G4, which suggested a binding configuration in which $\mathbf{G 5}$ occupies the remaining cavity of $\mathbf{G 1} \cdot \mathbf{G 4} \subset \mathbf{2}$, localised around the apertures (Figure 5b). Although the ${ }^{1} \mathrm{H}$ NMR spectrum at $233 \mathrm{~K}$ was broad, ESI-MS confirmed that G1 remained bound following the binding of G5. Three distinct internal binding sites were thus concurrently 
occupied in this structure: one dividing the central cavity (G4), one occupying a single compartment of this divided cavity (endo-bound G1), and another in the void created by this coordination (G5). Our methods thus allow for three distinct components to be brought into proximity, in a manner that may prove useful for applications in catalysis or allosteric binding regulation.

\section{Interlocked structures within 2}

As with 1, 2 was observed to bind suitably-sized linear 4,4'-dipyridyl guests (Figure 6a, Supplementary Section 8.5). The addition of 4,4'-dipyridyl naphthalenediimide (NDI) G6 to 2 gave a product having an ESI mass spectrum consistent with encapsulation (Figure S83). The ${ }^{1} \mathrm{H}$ NMR spectrum was broad, suggesting rapid scrambling of the guest among the three possible interior binding axes (Figure S81).

Electron deficient NDI units are known to bind to electron rich naphthalene units, with this interaction serving as a means for generating mechanically interlocked species. ${ }^{34}$ We hypothesised that G6, bound within 2 , might be threaded through a flexible macrocycle containing two cofacial naphthalene units (G7), thus inhibiting the motion of G6 within 2 (Figure 6b) and generating an encapsulated rotaxane guest (Supplementary Section 8.6).

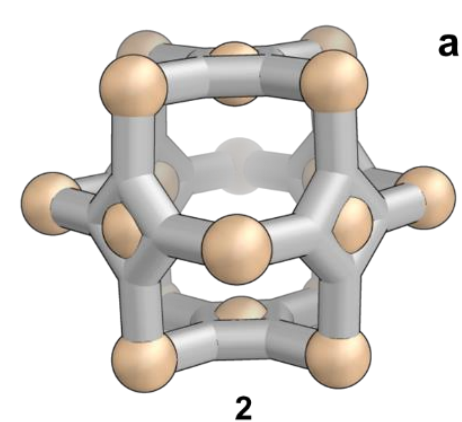

2

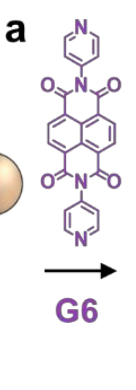

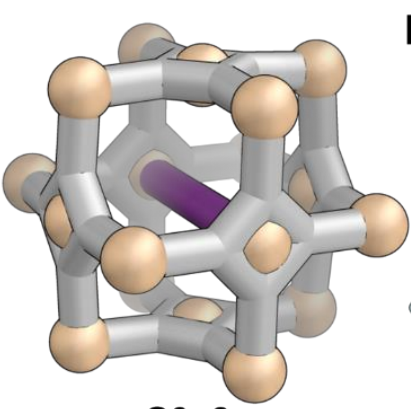

G6 $\subset 2$

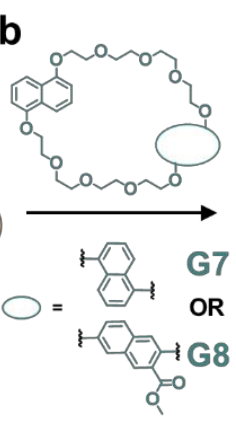

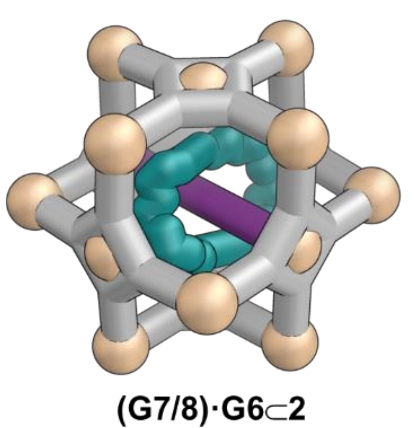

Figure 6. The formation of endohedral rotaxanes within 2. (a) G6 coordinated to opposite $\mathrm{Zn}^{\mathrm{II}}$ centres within 2. (b)

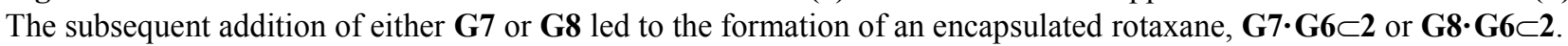

The addition of $\mathbf{G} 7$ to a $\mathrm{MeCN}$ solution of $\mathbf{G 6} \subset \mathbf{2}$ resulted in a sharpening of the ${ }^{1} \mathrm{H}$ NMR signals of the assembly, which displayed three distinct ligand environments. This observation is consistent with restricted tumbling of $\mathbf{G 7 \cdot G 6}$ within $\mathbf{2}$ on the NMR timescale, the apparent point symmetry of which was reduced from $O$ to $D_{4}$. Signals attributed to $\mathbf{G 7}$ were shifted upfield within 2, while signals attributed to $\mathbf{G 6}$ were at similar chemical shifts to those observed for $\mathbf{G 6} \subset \mathbf{2}$ (Figures S85-88). ${ }^{1} \mathrm{H}$ NOE correlations between 2 and G6, and G6 and G7 could be identified,

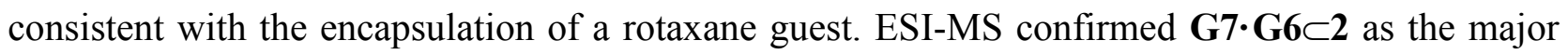


product. Combining G6 and G7 in $\mathrm{MeCN}$ in the absence of the cage led to the formation of an insoluble precipitate; rotaxane formation was observed only when axle G6 was threaded with cycle G7 after inclusion within the cage. A fast-exchange binding interaction was observed between $\mathbf{G 6}$ and $\mathbf{G 7}$ in a $1: 1 \mathrm{CDCl}_{3}: d_{6}$-DMSO solvent mixture, suggesting pseudo-rotaxane formation in the absence of $2 .{ }^{35}$ The slow disassembly of $\mathbf{2}$ at the concentration required for fluorescence spectroscopy $\left(10^{-7} \mathrm{M}\right)$ precluded the investigation of potential emissive quenching of the porphyrin units upon rotaxane encapsulation.

Employing lower-symmetry macrocycle G8 in place of G7 produced a sharper ${ }^{1} \mathrm{H}$ NMR spectrum of the host-guest species (Supplementary Section 8.6.2). In tandem with ESI-MS, 2D NMR confirmed the encapsulation of the asymmetric rotaxane G8. G6. Splitting of the $\beta$-pyridyl protons of G6 into two doublets, along with twofold desymmetrisation of the pyrrolic protons of the zinc porphyrin to which G6 was coordinated, suggested that the orientation of the macrocycle around the axle is fixed in place by coordination within 2: the rotaxane is rotating rapidly about its axle, but not tumbling within the cavity. No EXSY exchange cross-peaks were observed between

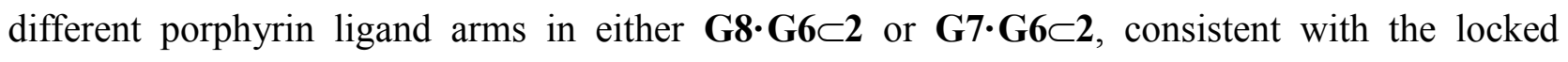

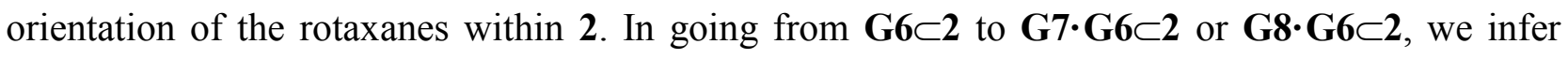
that increased steric bulk within the cage decreased guest motion, as reflected in the transition from broad-to-sharp NMR signals following axle binding to rotaxane threading. The adducts $\mathbf{G 6} \subset \mathbf{2}, \mathbf{G 7} \cdot \mathbf{G 6} \subset \mathbf{2}$ and $\mathbf{G 8} \cdot \mathbf{G 6} \subset \mathbf{2}$ may thus be considered as new, soluble molecular gyroscopes. ${ }^{36}$

\section{CONCLUSIONS}

Cages bearing a 24+ charge are able to overcome electrostatic repulsion to bind positivelycharged complex ions, generating encapsulated coordination complexes. These capsules bound three distinct components simultaneously, enabling the sequential division and occupation of their inner phases. The ability to manipulate the electronics of metal ions within these systems upon secondary coordination events highlights the utility of confinement effects in generating novel synthetic products and unearthing new molecular dynamics. None of the complexes bound within $\mathbf{1}$ or $\mathbf{2}$ have been reported before, nor could we prepare them outside the cavities of their respective cages. The inner phases of these cages thus provide unique chemical environments for selfassembly. New cage geometries with different cavity shapes will improve the range of assemblies that can be stabilised using this approach of coordination-directed supramolecular synthesis.

\section{ASSOCIATED CONTENT}


The Supporting Information for this paper is available free of charge on the ACS Publications website.

Synthetic details, characterisation data, and host-guest studies.

X-ray data for 1 (CCDC 1830497)

X-ray data for $\left[\mathrm{Cd}(\text { pyrazine })_{5}\left(\mathrm{H}_{2} \mathrm{O}\right)\right] \subset \mathbf{l}(\mathrm{CCDC} 1830496)$

\section{AUTHOR INFORMATION}

\section{Corresponding Author}

*E-mail:jirn34@,cam.ac.uk

\section{ORCID}

Felix J. Rizzuto: 0000-0003-2799-903X

Jonathan R. Nitschke: 0000-0002-4060-5122

\section{Funding Sources}

This work was supported by the UK Engineering and Physical Sciences Research Council (EPSRC EP/P027067/1) and the European Research Council (ERC 695009). The authors declare no competing financial interest.

\section{ACKNOWLEGMENTS}

F.J.R. acknowledges Cambridge Australia Scholarships and the Cambridge Trust for PhD funding, and W.J.R acknowledges the Marie Curie Academic-Industrial Initial Training Network on Dynamic Molecular Nanostructures (DYNAMOL). We thank Diamond Light Source for time on Beamline I19 (MT15768).

\section{REFERENCES}

(1) Haas, K. L., Franz, K. J., Chem. Rev. 2009, 109, 4921-4960.

(2) Liu, C., Colón, B. C., Ziesack, M., Silver, P. A., Nocera, D. G., Science 2016, 352, 12101213.

(3) Ohata, J., Ball, Z. T., J. Am. Chem. Soc. 2017, 139, 12617-12622.

(4) Ruiz-Castillo, P., Buchwald, S. L., Chem. Rev. 2016, 116, 12564-12649.

(5) Rodríguez-Jiménez, S., Feltham, H. L. C., Brooker, S., Angew. Chem. Int. Ed. 2016, 55, 15067-15071. 
(6) Cambridge Crystallographic Database Centre (CCDC), $<$ https://ccdc.cam.ac.uk/> accessed 26 February 2018.

(7) Tranchemontagne, D. J., Mendoza-Cortes, J. L., O'Keeffe, M., Yaghi, O. M., Chem. Soc. Rev. 2009, 38, 1257-1283.

(8) Otto, S., Furlan, R. L. E., Sanders, J. K. M., Science 2002, 297, 590-593.

(9) (a) Pike, S. D., Weller, A. S., Phil. Trans. R. Soc. A 2015, 373, 20140187; (b) Bloch, W. M., Champness, N. R., Doonan, C. J., Angew. Chem. Int. Ed. 2015, 54, 12860-12867.

(10) (a) Cook, T. R., Stang, P. J., Chem. Rev. 2015, 115, 7001-7045; (b) Chen, L.-J., Yang, H.B., Shionoya, M., Chem. Soc. Rev. 2017, 46, 2555-2576.

(11) Chifotides, H. T., Giles, I. D., Dunbar, K. R., J. Am. Chem. Soc. 2013, 135, 3039-3055.

(12) (a) Samanta, D., Galaktionova, D., Gemen, J., Shimon, L. J. W., Diskin-Posner, Y., Avram, L., Král, P., Klajn, R., Nat. Commun. 2018, 9, 641; (b) Freye, S., Hey, J., Torras-Galán, A., Stalke, D., Herbst-Irmer, R., John, M., Clever, G. H., Angew. Chem. Int. Ed. 2012, 51, 21912194.

(13) Rizzuto, F. J., Nitschke, J. R., Nat. Chem. 2017, 9, 903-908.

(14) (a) Cullen, W., Misuraca, M. C., Hunter, C. A., Williams, N. H., Ward, M. D., Nat. Chem. 2016, 8, 231-236; (b) Brown, C. J., Toste, F. D., Bergman, R. G., Raymond, K. N., Chem. Soc. Rev. 2015, 115, 3012-3035.

(15) (a) Yazaki, K., Akita, M., Prusty, S., Chand, D. K., Kikuchi, T., Sato, H., Yoshizawa, M., Nat. Commun. 2017, 8, 15914; (b) Rizzuto, F. J., Wu, W.-Y., Ronson, T. K., Nitschke, J. R., Angew. Chem. Int. Ed. 2016, 55, 7958-7962; (c) Rizzuto, F. J., Wood, D. M., Ronson, T. K., Nitschke, J. R., J. Am. Chem. Soc. 2017, 139, 11008-11011.

(16) Borsley, S., Cooper, J. A., Lusby, P. J., Cockroft, S. L., Chem - Eur. J. 2018, 24, 45424546.

(17) (a) Zhang, K., Yeung, M. C.-L., Leung, S. Y.-L., Yam, V. W.-W., Proc. Natl. Acad. Sci. USA 2017, 114, 11844-11849; (b) Cohen, E., Weissman, H., Shimoni, E., Kaplan-Ashiri, I., Werle, K., Wohlleben, W., Rybtchinski, B., Angew. Chem. Int. Ed. 2017, 56, 2203-2207; (c) Lee, J., Baek, K., Kim, M., Yun, G., Ko, Y. H., Lee, N.-S., Hwang, I., Kim, J., Natarajan, R., Park, C. G., Sung, W., Kim, K., Nat. Chem. 2014, 6, 97; (d) Sauvage, J.-P., Acc. Chem. Res. 1998, 31 , 611-619.

(18) (a) Talotta, C., Gaeta, C., Qi, Z., Schalley, C. A., Neri, P., Angew. Chem. Int. Ed. 2013, 52, 7437-7441; (b) Danon, J. J., Krüger, A., Leigh, D. A., Lemonnier, J.-F., Stephens, A. J., Vitorica-Yrezabal, I. J., Woltering, S. L., Science 2017, 355, 159-162; (c) Lehn, J.-M., Chem. Soc. Rev. 2007, 36, 151-160; (d) Ueda, Y., Ito, H., Fujita, D., Fujita, M., J. Am. Chem. Soc. 2017, 139, 6090-6093; (e) Lister, F. G. A., Le Bailly, B. A. F., Webb, S. J., Clayden, J., Nat. Chem. 2017, 9 , 420; (f) Su, X., Aprahamian, I., Chem. Soc. Rev. 2014, 43, 1963-1981; (g) Trinh, T., Liao, C., Toader, V., Barłóg, M., Bazzi, H. S., Li, J., Sleiman, H. F., Nat. Chem. 2017, 10, 184; (h) Beaudoin, D., Rominger, F., Mastalerz, M., Angew. Chem. Int. Ed. 2017, 56, 1244-1248; (i) O’Sullivan, M. C., Sprafke, J. K., Kondratuk, D. V., Rinfray, C., Claridge, T. D. W., Saywell, A., Blunt, M. O., O’Shea, J. N., Beton, P. H., Malfois, M., Anderson, H. L., Nature 2011, 469, 72; (j) Lewis, J. E. M., Beer, P. D., Loeb, S. J., Goldup, S. M., Chem. Soc. Rev. 2017, 46, 2577-2591; (k) Wilson, A., Gasparini, G., Matile, S., Chem. Soc. Rev. 2014, 43, 1948-1962; (1) Jin, Y., Wang, Q., Taynton, P., Zhang, W., Acc. Chem. Res. 2014, 47, 1575-1586; (m) Wang, H., Qian, X., Wang, K., Su, M., Haoyang, W.-W., Jiang, X., Brzozowski, R., Wang, M., Gao, X., Li, Y., Xu, B., Eswara, P., Hao, X.-Q., Gong, W., Hou, J.-L., Cai, J., Li, X., Nature Commun. 2018, 9, 1815.

(19) (a) Horiuchi, S., Murase, T., Fujita, M., J. Am. Chem. Soc. 2011, 133, 12445-12447; (b) Takezawa, H., Akiba, S., Murase, T., Fujita, M., J. Am. Chem. Soc. 2015, 137, 7043-7046.

(20) (a) Sanada, K., Ube, H., Shionoya, M., J. Am. Chem. Soc. 2016, 138, 2945-2948; (b) Amo-Ochoa, P., Jiménez-Aparicio, R., Perles, J., Torres, M. R., Gennari, M., Zamora, F., Cryst. Growth \& Design 2013, 13, 4977-4985.

(21) Favarger, F., Goujon-Ginglinger, C., Monchaud, D., Lacour, J., J. Org. Chem. 2004, 69, 8521-8524. 
(22) 5398 .

(23) 1653

6283; (b) Ed. 2003, 42, 3909-3913.

(26) (a) Kitazawa, T., Gomi, Y., Takahashi, M., Takeda, M., Enomoto, M., Miyazaki, A., Enoki, T., J. Mater. Chem. 1996, 6, 119-121; (b) Liu, D., Liu, Q., Li, Y., Wang, M., Yang, X., Wu, T., Moorefield, C., Wang, P., Newkome, G. R., Dalton Trans. 2015, 44, 11269-11273; (c) Carlucci, L., Ciani, G., Proserpio, D. M., Sironi, A., Angew. Chem. Int. Ed. 1995, 34, 1895-1898.

(27) von Krbek, L. K. S., Schalley, C. A., Thordarson, P., Chem. Soc. Rev. 2017, 46, 2622-

(28) Sanders, J. K. M., Bampos, N., Clyde-Watson, Z., Darling, S. L., Hawley, J. C., Kim, H.J., Mak, C. C., Webb, S. J., Axial coordination chemistry of metalloporphyrins. In The Porphyrin Handbook, Kadish, K. M.; Smith, K. M.; Guilard, R., Eds. Academic Press: London, UK, 2000; Vol. 15, pp 1-48.

(29) Venkataramani, S., Jana, U., Dommaschk, M., Sönnichsen, F. D., Tuczek, F., Herges, R., Science 2011, 331, 445-448.

(30) Kadish, K. M., Bottomley, L. A., Beroiz, D., Inorg. Chem. 1978, 17, 1124-1129.

(31) (a) Kumar, R. K., Diskin-Posner, I., Goldberg, I., J. Incl. Phenom. Macrocycl. Chem. 2000, 37, 219-230; (b) Litvinov, A. L., Konarev, D. V., Kovalevsky, A. Y., Neretin, I. S., Coppens, P., Lyubovskaya, R. N., Cryst. Growth \& Design 2005, 5, 1807-1819.

(32) (a) Choi, E.-Y., Barron, P. M., Novotny, R. W., Son, H.-T., Hu, C., Choe, W., Inorg. Chem. 2009, 48, 426-428; (b) Fidalgo-Marijuan, A., Barandika, G., Bazán, B., Urtiaga, M.-K., Arriortua, M. I., CrystEngComm 2013, 15, 4181-4188; (c) Mansour, A., Belghith, Y., Belkhiria, M. S., Bujacz, A., Guérineau, V., Nasri, H., J. Porphyr. Phthalocyanines 2013, 17, 1094-1103.

(33) (a) Hambright, P., Chem. Commun. (London) 1967, 10.1039/C19670000470, 470-471;

(b) Heitmann, G., Schütt, C., Herges, R., Eur. J. Inorg. Chem. 2016, 2016, 3817-3823.

(34) Bruns, C. J., Stoddart, J. F., The nature of the mechanical bond: from molecules to machines. John Wiley \& Sons, Inc.: New Jersey, 2017.

(35) Ashton, P. R., Baxter, I., Fyfe, M. C. T., Raymo, F. M., Spencer, N., Stoddart, J. F., White, A. J. P., Williams, D. J., J. Am. Chem. Soc. 1998, 120, 2297-2307.

(36) (a) Dominguez, Z., Dang, H., Strouse, M. J., Garcia-Garibay, M. A., J. Am. Chem. Soc. 2002, 124, 2398-2399; (b) Day, A. I., Blanch, R. J., Arnold, A. P., Lorenzo, S., Lewis, G. R., Dance, I., Angew. Chem. Int. Ed. 2002, 41, 275-277.

\section{Table of contents graphic}
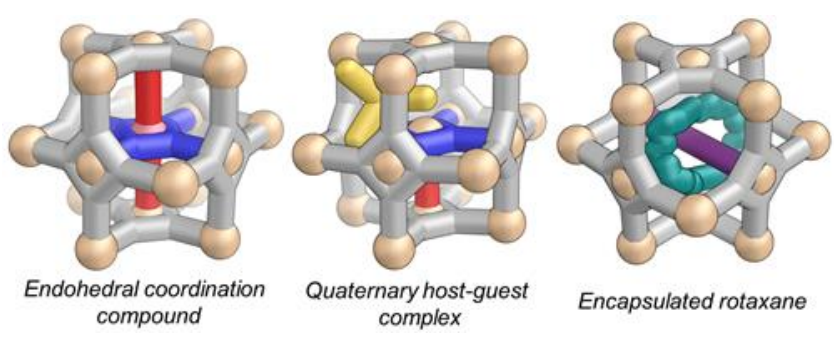